Pierce, C. W., Cullen, S. E., Kapp, J. A., Schwartz, B. D., and Shreffler, D. C. (eds.): Ir Genes: Past, Present, and Future, The Humana Press Inc., Clifton, New Jersey, 1983, 98 figures, 129 tables, 621 pages, XXVI, cloth, $\$ 64.50$

This book represents a compilation of the papers presented at the Fifth Ir Gene Workshop held in St. Louis, Missouri, August 28-31, 1982. Most remarkable about this book is the speed with which it was published; most misleading about it is its title. Although it is still unclear exactly how Ir genes determine immune responsiveness, it is certain that the genes are identical with the major histocompatibility complex (MHC) genes coding for the class I and class II molecules. Control of immune responsiveness is one of the pleiotropic effects of these genes resulting from the recognition Mhe molecules by $\mathrm{T}$ lymphocytes.

Traditionally the MHC genes have been studied by histogenetic, serological and biochemical methods. More recently, techniques of gene cloning and DNA sequencing, T- and B-cell hybridomas, and cloned T-cell lines have been applied to the analysis of the Mhc genes. Both the traditional and the more modern approaches are represented in this book. The results are centered around the following topics: genetic organization of class II genes; chemistry of class II gene products and DNA cloning of class II genes; class II gene function - cellular site(s) and mechanism(s) of action; the role of class II antigens in restricted cell interactions; lessons from T-cell clones and T-cell hybridomas; where from here?

The majority of the papers do not describe new data, but rather summarize results already published under another title elsewhere. The only possible justification for publishing the data again is that publishing gives the authors an opportunity to present them in a more informal way for easier reading. Missing are the general discussions and possible conclusions from the materials presented in each section. Such summaries would have been more informative than the rehashed papers because they could have served as an orientation point for future work. Without them the book merely reviews selected topics by selected (unrepresentative) scientists. The only exception is the last section in which the authors summarize the field and attempt to predict future trends.

From the results presented it seems that in the near future the greatest progress can be expected from the gene cloning and DNA sequencing experiments because these techniques will localize the genes of the Mhc complex precisely and thus solve the as yet unresolved questions concerning the problematic loci such as $J$ or $C$.

Whether the book will satisfy anyone is questionable. For workers in the field it will not bring anything new. For beginners, the book, without summaries and general reviews, will appear too specialized.

Antonio Juretić

\title{
Erratum
}

\section{An Alpha Globin Pseudogene Is Located Within the Mouse $t$ Complex}

\author{
Howard S. Fox, Lee M. Silver, and Gail R. Martin
}

Immunogenetics 19: 125-130, 1984

In the listing of the Hba-ps4 alleles carried by inbred strains of mice, the BALBc/J genotype was mistakenly listed as carrying the prototype of the $H b a-p s 4^{b}$ allele. BALBc/J mice actually carry the $H b a-p s 4^{c}$ allele. The $H b a-p s 4^{b}$ allele is defined by the pattern carried by $\mathrm{C} 57 \mathrm{BL} / 6 \mathrm{~J}$ mice. 